\title{
Looking for a generic inhibitor of amyloid-like fibril formation among flavone derivatives
}

Tomas Šneideris, Lina Baranauskienė, Jonathan G Cannon, Rasa Rutkienė, Rolandas Meškys, Vytautas Smirnovas

A range of diseases is associated with amyloid fibril formation. Despite different proteins being responsible for each disease, all of them share similar features including beta-sheetrich secondary structure and fibril-like protein aggregates. A number of proteins can form amyloid-like fibrils in vitro, resembling structural features of disease-related amyloids. Given these generic structural properties of amyloid and amyloid-like fibrils, generic inhibitors of fibril formation would be of interest for treatment of amyloid diseases. Recently we identified five outstanding inhibitors of insulin amyloid-like fibril formation among the pool of 265 commercially available flavone derivatives. Here we report testing of these five compounds and of epi-gallocatechine-3-gallate (EGCG) on aggregation of alpha-synuclein and beta-amyloid. We used a Thioflavin T (ThT) fluorescence assay, relying on halftimes of aggregation as the measure of inhibition. This method avoids large numbers of false positive results. Our data indicate that four of the five flavones and EGCG inhibit alpha-synuclein aggregation in a concentration-dependent manner. However none of these derivatives were able to increase halftimes of aggregation of beta-amyloid. 


\section{Looking for a generic inhibitor of amyloid-like fibril formation among}

\section{2 flavone derivatives}

3 Tomas Sneideris ${ }^{1}$, Lina Baranauskiene ${ }^{1}$, Jonathan G. Cannon ${ }^{2}$, Rasa Rutkiene ${ }^{3}$, Rolandas

4 Meskys $^{3}$, and Vytautas Smirnovas ${ }^{1 *}$

$5{ }^{I}$ Department of Biothermodynamics and Drug Design, Vilnius University Institute of

6 Biotechnology, Vilnius, Lithuania

$7 \quad$ 2Department of Natural Sciences and Engineering, Middle Georgia State University, Cochran,

8 Georgia, USA

$9{ }^{3}$ Department of Molecular Microbiology and Biotechnology, Vilnius University Institute of

10 Biochemistry, Vilnius, Lithuania

11 *Correspondence to: vytautas.smirnovas@bti.vu.lt

\section{Abstract}

13 A range of diseases is associated with amyloid fibril formation. Despite different proteins being 14 responsible for each disease, all of them share similar features including beta-sheet-rich

15 secondary structure and fibril-like protein aggregates. A number of proteins can form amyloid-

16 like fibrils in vitro, resembling structural features of disease-related amyloids. Given these

17 generic structural properties of amyloid and amyloid-like fibrils, generic inhibitors of fibril

18 formation would be of interest for treatment of amyloid diseases.

19 Recently we identified five outstanding inhibitors of insulin amyloid-like fibril formation among

20 the pool of 265 commercially available flavone derivatives. Here we report testing of these five 
21 compounds and of epi-gallocatechine-3-gallate (EGCG) on aggregation of alpha-synuclein and

22 beta-amyloid. We used a Thioflavin $\mathrm{T}$ (ThT) fluorescence assay, relying on halftimes of

23 aggregation as the measure of inhibition. This method avoids large numbers of false positive

24 results. Our data indicate that four of the five flavones and EGCG inhibit alpha-synuclein

25 aggregation in a concentration-dependent manner. However none of these derivatives were able

26 to increase halftimes of aggregation of beta-amyloid. 


\section{Introduction}

Amyloid fibril formation is related to a number of fatal neurodegenerative disorders, such as Alzheimer's and Parkinson's diseases and transmissible spongiform encephalopaties. One of the strategies for pharmacological intervention is to inhibit protein aggregation into amyloid structure (Bieschke, 2013). Different proteins and peptides form amyloid aggregates in case of each disease, but all aggregates share similar physicochemical and structural properties (Chiti \& Dobson, 2006). Structurally similar aggregates, referred to as amyloid-like fibrils (Nelson \& Eisenberg, 2006), can be formed from both disease-related and unrelated proteins and peptides in vitro. This led to the idea that amyloid-like structure may be a generic property of polypeptide chains (Chiti \& Dobson, 2006). Given structural similarities of different amyloid and amyloidlike fibrils, there is a possibility that generic inhibitors of amyloid fibril formation may exist.

A number of small molecules were reported as inhibitors of amyloid-like fibril formation (Doig \& Derreumaux, 2015; Seneci, 2015), some of them reached different phases of clinical trials, but none is approved as a drug yet (Mangialasche et al., 2010; Seneci, 2015). One of the best-known inhibitors of protein amyloid fibrillation is epi-gallocatechine-3-gallate (EGCG). There are reports, suggesting its inhibitory effect on the fibril formation of amyloid beta (Abeta) peptide and alpha-synuclein (Ehrnhoefer et al., 2008; Roberts \& Shorter, 2008; Bieschke et al., 2010), huntingtin (Ehrnhoefer et al., 2006), mammalian and yeast prions (Rambold et al., 2008; Roberts et al., 2009), kappa-casein (Hudson et al., 2009a), transthyretin (Ferreira et al., 2009; Ferreira, Saraiva \& Almeida, 2011), islet amyloid polypeptide (Meng et al., 2010), Plasmodium falciparum merozoite surface protein 2 (Chandrashekaran et al., 2010, 2011), human insulin (Wang, Dong \& Sun, 2012), hen egg white lysozyme (Ghosh, Pandey \& Dasgupta, 2013), tau protein (Wobst et al., 2015), and human parathyroid hormone (Gopalswamy et al., 2015). The 
51 large number and variety of targets suggested that EGCG is a genuine generic inhibitor of 52 amyloid fibril formation. Resveratrol is another compound inhibiting amyloid-like fibril 53 formation of several proteins, including Abeta (Feng et al., 2009; Ladiwala et al., 2010), alpha54 synuclein (Herva et al., 2014), and islet amyloid polypeptide (Mishra et al., 2009). A number of different flavone derivatives, including morin, quercetin, fisetin and luteolin were reported as inhibitors of Abeta fibrillation (Ono et al., 2003; Akaishi et al., 2008; Ushikubo et al., 2012). Luteolin, quercetin and fisetin can inhibit transthyretin aggregation (Trivella et al., 2012), and luteolin also inhibits fibrillation of insulin (Malisauskas et al., 2015). There is a report on islet amyloid polypeptide inhibition by morin (Noor, Cao \& Raleigh, 2012). Our interest in flavones as inhibitors of amyloid-like fibril formation was especially raised by the study of Akaishi et al, which suggested that inhibitory effect of flavone derivatives is dependent on the number and positions of hydroxyl group around the flavone backbone (Akaishi et al., 2008) and a subsequent work of Ushikubo et al, which designed a new flavone-derived inhibitor of Abeta aggregation 64 (Ushikubo et al., 2012).

One of the major problems in the detection of anti-amyloid compounds is ambiguity of the methods used for screening. A significant portion of the studies referenced relied only on changes in maximal ThT fluorescence intensity to establish inhibition of fibril formation (Ono et al., 2003; Akaishi et al., 2008; Ushikubo et al., 2012), sometimes leading to controversial results. For example Ono et al claimed kaempferol as an inhibitor (Ono et al., 2003), while Akaishi et al showed it to enhance Abeta fibril formation (Akaishi et al., 2008). Other studies have described how ThT fluorescence intensity can be affected by different compounds (Foderà et al., 2008; Hudson et al., 2009b; Noormägi et al., 2012). 

checked their effect on the aggregation of alpha-synuclein and Abeta.<smiles>O=c1cc(-c2ccc(O)cc2)oc2cc(O)c(O)c(O)c12</smiles>

Scutellarein<smiles>O=c1cc(-c2ccc(O)c(O)c2)oc2cc(O)cc(O)c12</smiles>

Luteolin<smiles>O=c1cc(-c2ccccc2O)oc2c(O)c(O)ccc12</smiles>

7,8,2'-trihydroxyflavone<smiles>O=c1c(O)c(-c2cc(O)c(O)cc2O)oc2ccc(O)cc12</smiles>

$3,6,2^{\prime}, 4^{\prime}, 5^{\prime}$-pentahydroxyflavone<smiles>O=c1c(O)c(-c2ccc(O)c(O)c2)oc2c(O)c(O)cc(O)c12</smiles>

Gossypetin

Figure 1. The best flavone inhibitors of insulin amyloid-like fibril formation. 
84 Flavones were purchased from Indofine Chemical Company and EGCG was purchased from

85 Sigma. Flavones and EGCG were dissolved at a concentration of $20 \mathrm{mM}$ in dimethylsulfoxide

86 (DMSO) and stored in the dark at room temperature for up to two weeks.

87

88

89

90

91

92

93

94

95

96

97

98

99

100

101

102

103

104

105

106

Production of alpha-synuclein

E. coli BL-21(DE3) (Invitrogen) was used as the host strain for the over-expression of alphasynuclein. For this purpose, cells harbouring a plasmid pRK172 were grown in a standard NB medium supplemented with $50 \mu \mathrm{g} / \mathrm{mL}$ ampicillin. $200 \mathrm{~mL}$ of medium was inoculated with $1 \mathrm{~mL}$ of the overnight culture and incubated at $30{ }^{\circ} \mathrm{C}$ until an $\mathrm{OD}_{600}$ of $0.7-0.8$ was reached. Protein expression was then induced by adding IPTG to a final concentration of $0.2 \mathrm{mM}$, and the incubation was continued for additional $18 \mathrm{~h}$. The cells were harvested by centrifugation for 30 min. at $4000 \mathrm{~g}\left(4^{\circ} \mathrm{C}\right)$, resuspended in $20 \mathrm{mM}$ Tris- $\mathrm{HCl}$ buffer (pH 8.0), containing $0.5 \mathrm{M} \mathrm{NaCl}, 1$ $\mathrm{mM}$ PMSF and $1 \mathrm{mM}$ EDTA and disrupted by sonication at $22 \mathrm{kHz}$ for $3 \mathrm{~min}$., using $50 \%$ amplitude. To remove cellular debris the cell lysate was centrifuged at $10000 \mathrm{~g}$ for $20 \mathrm{~min}$ at 4 ${ }^{\circ} \mathrm{C}$. After centrifugation cellular extract was subjected to a $20 \mathrm{~min}$. heat treatment using a water bath at $100{ }^{\circ} \mathrm{C}$. Cell extract with aggregated proteins was immediately centrifuged at $10000 \mathrm{~g}$ for $30 \mathrm{~min}$. at $4{ }^{\circ} \mathrm{C}$. The resulting clear supernatant was dialysed at $4{ }^{\circ} \mathrm{C}$ for $18 \mathrm{~h}$ against $20 \mathrm{mM}$ Tris- $\mathrm{HCl}$ buffer (pH 8.0), containing $1 \mathrm{mM}$ EDTA and 1mM DTT (buffer A). The desalted sample was applied at a flow rate of $1 \mathrm{~mL} / \mathrm{min}$ onto a $5 \mathrm{~mL}$ HiTrap ANX HP column (GE Healthcare), previously equilibrated with buffer A. After washing with 5 column volumes of buffer $\mathrm{A}$, the recombinant protein was eluted using a linear gradient of $0-1 \mathrm{M} \mathrm{NaCl}$ in buffer $\mathrm{A}$. The eluted from the column fractions were checked by SDS electrophoresis, pooled and dialyzed overnight against buffer A. The dialyzed protein solution was applied at a flow rate of 0.5 $\mathrm{mL} / \mathrm{min}$ onto second ion exchange $1 \mathrm{~mL}$ HiTrap Q XL column (GE Healthcare) equilibrated 
107 with buffer A. After a 5 column volume wash with buffer A, alpha-synuclein was eluted over a

108 linear gradient of $0-1 \mathrm{M} \mathrm{NaCl}$ in buffer $\mathrm{A}$. The major peak eluted from the column was checked

109 by electrophoresis, pooled and dialyzed overnight against $5 \mathrm{mM}$ ammonium carbonate buffer

110 (pH 7.6). Desalted protein samples were flash-frozen, lyophilized and stored at $-20{ }^{\circ} \mathrm{C}$ until use.

111 The homogeneity of protein was verified by SDS-PAGE. Protein concentration was determined

112 using the Lowry method with bovine serum albumin as the standard.

113 Production of Abeta

114 The expression vector for Abeta42 in E. coli was described previously (Walsh et al., 2009;

115 Vignaud et al., 2013). The recombinant Abeta peptide was expressed in E. coli BL11621 Star $^{\mathrm{TM}}$ (DE3) (Invitrogen) and purified similarly to a previously described method (Walsh et

117 al., 2009; Hellstrand et al., 2010; Vignaud et al., 2013). The expression vector for Abeta42

118 peptide was transformed into $\mathrm{Ca}^{2+}$-competent $E$. coli cells by heat shock and spread on LB agar

119 plates containing ampicillin $(100 \mu \mathrm{g} / \mathrm{mL})$. Single colonies were used to inoculate $100 \mathrm{~mL}$

120 overnight cultures in LB medium with ampicillin $(100 \mu \mathrm{g} / \mathrm{mL})$. The next morning $1 \mathrm{~mL}$ of

121 overnight culture was transferred to $400 \mathrm{~mL}$ of auto-inductive ZYM-5052 medium (Studier,

122 2005) containing ampicillin $(100 \mu \mathrm{g} / \mathrm{mL})$ and grown for $24 \mathrm{~h}$. The cell suspension was

123 centrifuged at $5000 \mathrm{~g}$ and $4{ }^{\circ} \mathrm{C}$ for $15 \mathrm{~min}$. The cell pellet was frozen. The frozen cell pellet from

124 3.6 L culture was thawed, homogenized with Potter-Elvehjem homogenizer in a total of $100 \mathrm{~mL}$

125 buffer B (10 mM Tris/HCl pH 8.0, 1mM EDTA) and sonicated for $10 \mathrm{~min}$ on ice (30s/30s horn,

$12650 \%$ duty cycle). Cell pellet was centrifuged at $18000 \mathrm{~g}$ and $4{ }^{\circ} \mathrm{C}$ for $15 \mathrm{~min}$. The supernatant

127 was removed, and the pellet was resuspended twice in $100 \mathrm{~mL}$ of buffer $\mathrm{B}$, homogenized and

128 centrifuged as above. The third supernatant was removed and the pellet was resuspended in 50

$129 \mathrm{~mL}$ of buffer $\mathrm{C}$ (8 M urea, $10 \mathrm{mM}$ Tris $\mathrm{HCl} \mathrm{pH}$ 8.0, $1 \mathrm{mM}$ EDTA), homogenized and centrifuged 
130 as above, resulting in clear solution. The urea-solubilized inclusion bodies $(50 \mathrm{~mL})$ were diluted

131 with $150 \mathrm{~mL}$ of buffer $\mathrm{C}$, added to $50 \mathrm{~mL}$ DEAE-sepharose equilibrated in buffer $\mathrm{C}$, and gently

132 agitated $(80 \mathrm{rpm})$ for $30 \mathrm{~min}$ at $4{ }^{\circ} \mathrm{C}$. The slurry was then applied to a Büchner funnel with

133 Fisherbrand glass microfibers paper on a vacuum glass bottle. Later, the resin was washed with

$13450 \mathrm{~mL}$ of buffer $\mathrm{C}$ and then with $50 \mathrm{~mL}$ of buffer $\mathrm{C}$ with $25 \mathrm{mM} \mathrm{NaCl}$ followed by four aliquots

135 of buffer $\mathrm{C}$ with $125 \mathrm{mM} \mathrm{NaCl}$. Each aliquot was incubated with the resin for $5 \mathrm{~min}$ before

136 collection under vacuum. The presence of the peptide in aliquots was tested using Tricine SDS-

137 PAGE (Schägger, 2006). Combined aliquots $(200 \mathrm{~mL})$ were centrifuged through $30 \mathrm{kDa}$

138 molecular weight cutoff (MWCO) filter, and finally concentrated approximately twenty fold

139 using a $3 \mathrm{kDa}$ MWCO filter. The purified peptide was frozen in $1 \mathrm{~mL}$ aliquots. Aliquots of

140 purified peptide were thawed, diluted with $3 \mathrm{~mL}$ of buffer $\mathrm{D}(8 \mathrm{M} \mathrm{GuHCl}, 50 \mathrm{mM}$ Tris/HCl $\mathrm{pH}$

141 8.0) and concentrated to the final volume of $\sim 300 \mu \mathrm{L}$ using $3 \mathrm{kDa}$ MWCO concentrator.

142 Concentrated samples were loaded on a Tricorn 10/300 column (packed with Superdex 75

143 gelfiltration resin), and eluted at $1 \mathrm{~mL} / \mathrm{min}$ using buffer $\mathrm{E}(20 \mathrm{mM}$ sodium phosphate $\mathrm{pH} 8.0$,

$144200 \mu \mathrm{M}$ EDTA). Collected fractions $(2 \mathrm{~mL})$ were diluted with $6 \mathrm{~mL}$ of buffer $\mathrm{D}$, concentrated,

145 and the chromatography was repeated. After repetitive purification the Abeta monomer peak was

146 collected on ice. The amount of purified Abeta was calculated by integration of the

147 chromatographic UV absorbance peak, using extinction coefficient $\mathrm{E}_{280}=1490 \mathrm{M}^{-1} \mathrm{~cm}^{-1}$.

148 Aggregation of Abeta

149 Freshly purified (within 30 minutes after gelfiltration) monomeric Abeta42 solution was 150 supplemented with $50 \mu \mathrm{M}$ ThT and diluted using buffer E containing $50 \mu \mathrm{M}$ ThT to reach 151 different concentrations (1-6 $\mu \mathrm{M})$. For the inhibition experiments $216,36,6,1$, and $0.167 \mu \mathrm{M}$ 152 solutions of flavones in buffer D, containing $2 \%$ DMSO and $50 \mu \mathrm{M}$ ThT were prepared. 
153 Monomeric $6 \mu \mathrm{M}$ Abeta42 solution was mixed with these flavone derivative solutions (or with

154 buffer E containing $2 \%$ DMSO as a control) in a 1:1 ratio. Each sample was divided into three

$155100 \mu \mathrm{L}$ aliquots into wells of a 96 well non-binding half-area plate (Corning NBS ${ }^{\mathrm{TM}}$ ). Kinetics of

156 aggregation was followed at $37{ }^{\circ} \mathrm{C}$ temperature and constant shaking $(960 \mathrm{rpm})$ using Synergy

157 H4 Hybrid Multi-Mode (Biotek) microplate reader. The intensity of ThT fluorescence was

158 measured through the bottom of the plate every 3 min using $440 \mathrm{~nm}$ excitation and $482 \mathrm{~nm}$

159 emission.

160 Aggregation of alpha-synuclein

161 Alpha-synuclein was dissolved in $30 \mathrm{mM}$ Tris- $\mathrm{HCl}$ buffer $(\mathrm{pH} 7.5)$, containing $0.05 \%$ sodium

162 azide and $50 \mu \mathrm{M}$ ThT. For the study of the concentration dependence of fibrillation, a range of

163 alpha-synuclein concentrations between $1-5 \mathrm{mg} / \mathrm{mL}(69-345 \mu \mathrm{M})$ was used, and for inhibition

164 studies $300 \mu \mathrm{M}$ final concentration was used. For the inhibition experiments 450, 375, 300, 225,

165150 , and $75 \mu \mathrm{M}$ solutions of flavones in $30 \mathrm{mM}$ Tris- $\mathrm{HCl}$ buffer $(\mathrm{pH} 7.5)$, containing $0.05 \%$

166 sodium azide, 2.25\% DMSO, and $50 \mu \mathrm{M}$ ThT were prepared. The $300 \mu \mathrm{M}$ alpha-synuclein

167 solution was mixed with flavones in a 1:1 ratio. Each sample was divided into three $160 \mu \mathrm{L}$

168 aliquots into wells of a 96 well plate (Fisherbrand) and one $\sim 3 \mathrm{~mm}$ glass bead was added into

169 each well. Kinetics of aggregation was followed at $60{ }^{\circ} \mathrm{C}$ temperature and constant shaking $(960$

170 rpm) using Synergy H4 Hybrid Multi-Mode microplate reader. The intensity of ThT

171 fluorescence was measured through the bottom of the plate every 2 min using $440 \mathrm{~nm}$ excitation

172 and $482 \mathrm{~nm}$ emission.

173 Extraction of relative $t_{50}$ and $I_{\max }$ values 
174 Maximal fluorescence intensities and halftimes of aggregation were obtained by fitting 175 experimental data using following sigmoidal equation:

$$
I=I_{\min }+\frac{\left(I_{\max }-I_{\text {min }}\right) * x^{n}}{t_{50}^{n}+x^{n}}
$$

177

178

where $I$ is the intensity of fluorescence, $\mathrm{x}$ is time, $\mathrm{t}_{50}$ is the time to $50 \%$ of maximal fluorescence intensity, $I_{\min }$ and $I_{\max }$ are the minimal and maximal intensity of ThT fluorescence and $\mathrm{n}$ is the Hill coefficient. Fitting was performed using Origin 8.1 software. Extracted $t_{50}$ and $I_{\max }$ values in the presence of flavone derivatives were divided by the values for the control samples to obtain relative $t_{50}$ and $I_{\max }$. Average values and errors were calculated using three different batch preparations of flavones and three samples within each batch (a total of 9 repeats per flavone derivative).

\section{Congo Red spectroscopic assay}

The assay was performed as described previously (Nilsson, 2004). Briefly, $7 \mathrm{mg} / \mathrm{mL}$ Congo Red stock solution was prepared in $30 \mathrm{mM}$ Tris buffer, $\mathrm{pH} 7.5$, and filtered through $0.22 \mu \mathrm{m}$ syringe filter and stored at room temperature for up to a week. Alpha-synuclein samples were taken at different times of aggregation. $50 \mu \mathrm{L}$ of alpha-synuclein sample was mixed with $50 \mu \mathrm{L}$ of 70 $\mu \mathrm{g} / \mathrm{mL}$ Congo Red (freshly prepared from stock solution) and incubated for $30 \mathrm{~min}$ at room temperature in 96 well non-binding half-area plate (Corning NBSTM). Spectra were recorded using Synergy H4 Hybrid Multi-Mode (Biotek) microplate reader. In case of Abeta, $35 \mu \mathrm{g} / \mathrm{mL}$ of Congo Red were added to the $15 \mu \mathrm{M}$ peptide samples at the beginning of the reaction. $100 \mu \mathrm{L}$ aliquots were transferred into wells of a 96 well non-binding half-area plate (Corning NBSTM). The plate was incubated at $37{ }^{\circ} \mathrm{C}$ temperature, and spectra were recorded at different time points 
195

196

197 198

using Synergy H4 Hybrid Multi-Mode (Biotek) microplate reader. To get differential spectra, the corresponding spectrum at zero time point was mathematically subtracted from the spectra at later time points.

Atomic force microscopy (AFM)

For atomic force microscopy experiments, $20 \mu \mathrm{L}$ of the sample and $10 \mu \mathrm{L}$ of $1 \mathrm{M} \mathrm{HCl}$ (protein fibrils in neutral/basic buffer have net negative charge and poorly adsorb on the mica) were mixed on freshly cleaved mica and left to adsorb for $1 \mathrm{~min}$, the sample was rinsed with several $\mathrm{mL}$ of water and dried gently using airflow. AFM images were recorded in the Tapping-in-Air mode at a drive frequency of approximately $300 \mathrm{kHz}$, using a Dimension Icon (Bruker, Santa Barbara, CA, USA) scanning probe microscope system. Aluminium-coated silicon tips (RTESPA-300) from Bruker were used as a probe.

\section{Results}

The first step of our study was the optimization of kinetic assays of Abeta and alpha-synuclein. As the best flavone inhibitors increased $t_{50}$ of insulin aggregation up to 24 times (Malisauskas et al., 2015), we tried to find conditions, where $t_{50}$ values of Abeta and alpha-synuclein aggregation would not exceed several hours. A way to get fast and highly reproducible kinetics of Abeta42 aggregation was recently described by the Linse group (Hellstrand et al., 2010). We were able to use it with similar results (Fig.2A). Alpha-synuclein aggregates slower than Abeta, however the rate of aggregation can be increased using agitation, beads, and higher temperature (Buell et al., 2014). The dependence of $t_{50}$ values on the concentration of alpha-synuclein is shown in figure 
216 2B. For further experiments we chose the optimal concentrations of peptides $(3 \mu \mathrm{M}$ for Abeta 217 and $150 \mu \mathrm{M}$ for alpha-synuclein).
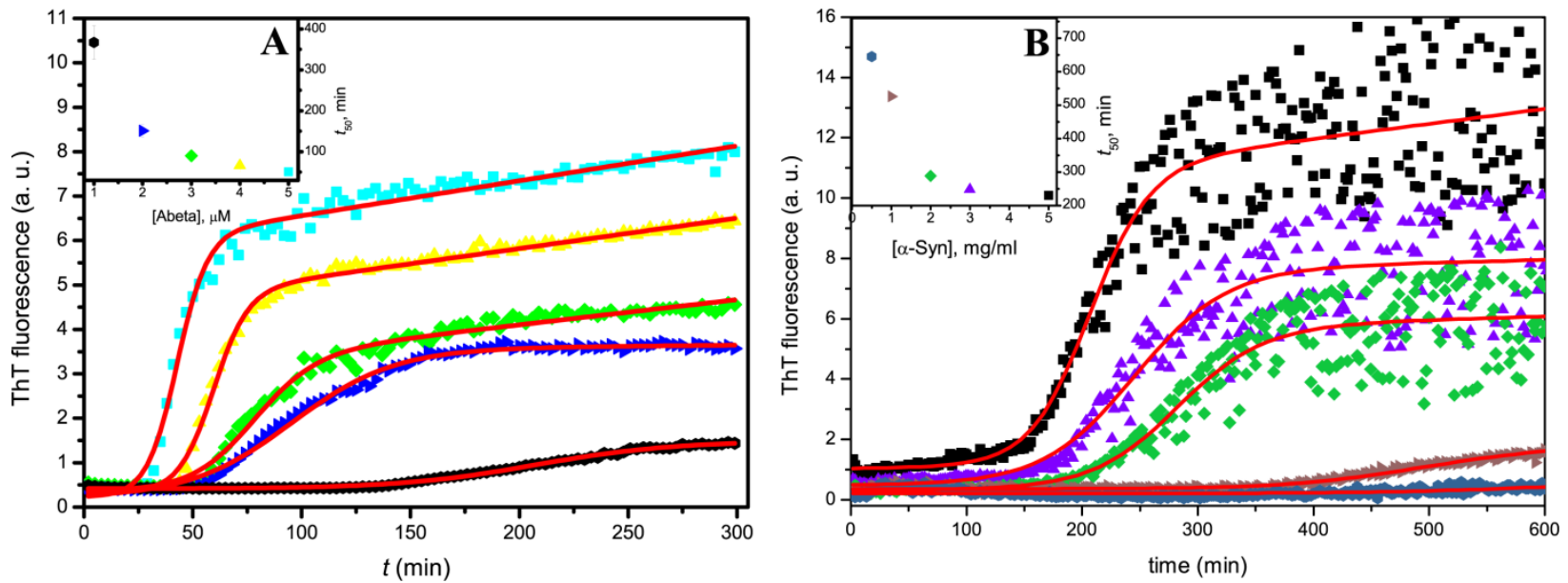

Figure 2. Concentration dependence of Abeta (A), and alpha-synuclein (B) aggregation kinetics. Raw data at different peptide concentrations is represented by scatter plots of different colors; fitting is represented by red curves. Inserts show concentration dependences of $t_{50}$ values and also serves as color-code legends.

The impact of flavones on ThT fluorescence intensity and $t_{50}$ values of alpha-synuclein aggregation is summarized in the figure 3. The effect of luteolin differs from other flavones. ThT

224 fluorescence is strongly affected even by lowest luteolin concentrations, but relative $t_{50}$ values stay close to 1 . Other flavones quench ThT fluorescence and increase the time of alpha-synuclein aggregation in a concentration-dependent manner. The inhibitory effect of gossypetin looks

227 about twice lower than scutellarein, 7,8,2'-trihydroxyflavone or 3,6,2',4',5'-pentahydroxyflavone. 

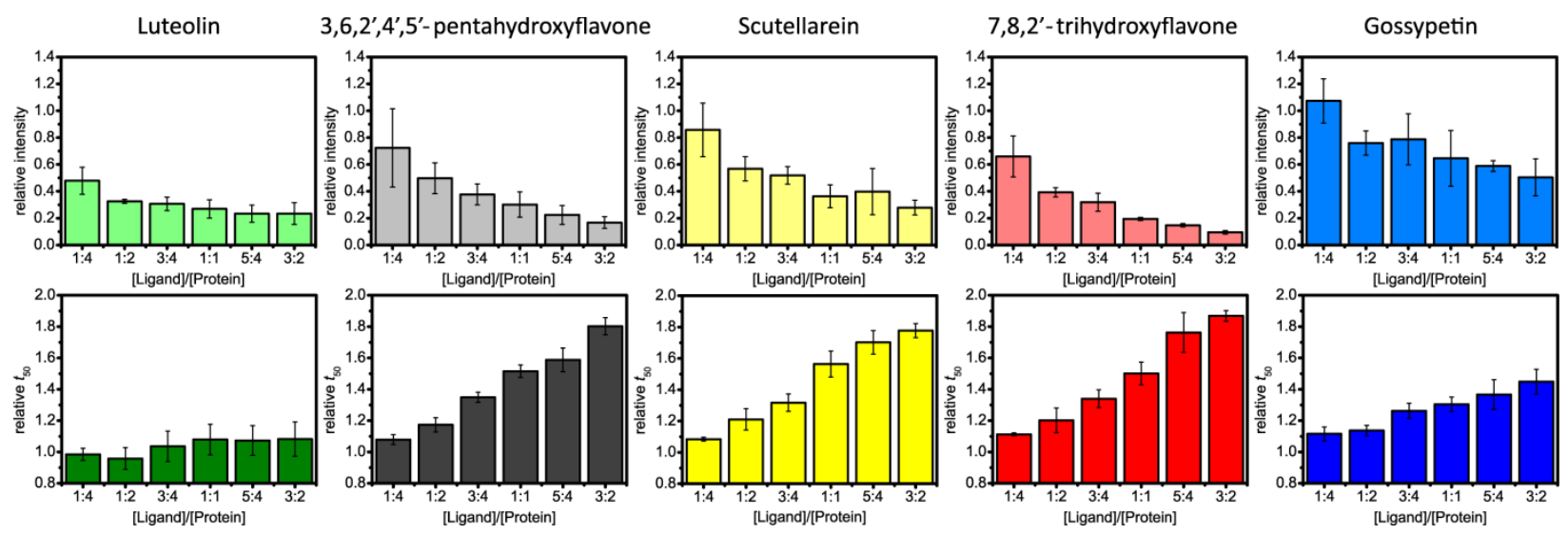

Figure 3. Effect of flavones on the aggregation of alpha-synuclein. Each flavone derivative is represented by different color. Relative ThT fluorescence intensities are shown in light colors (top row) and relative halftimes of aggregation in dark colors (bottom row).

232 The complementary analysis using Congo Red spectroscopic assay gave similar results (Fig. 4). Spectral maxima at $\sim 540 \mathrm{~nm}$ show the fastest and highest increases in the control sample and in

234 the presence of luteolin. In the presence of the rest of the flavones there is just a minor rise

235 within 10 hours and smaller final absorbance after 24 hours of incubation. The data suggest all tested flavones except luteolin inhibit aggregation of alpha-synuclein. 

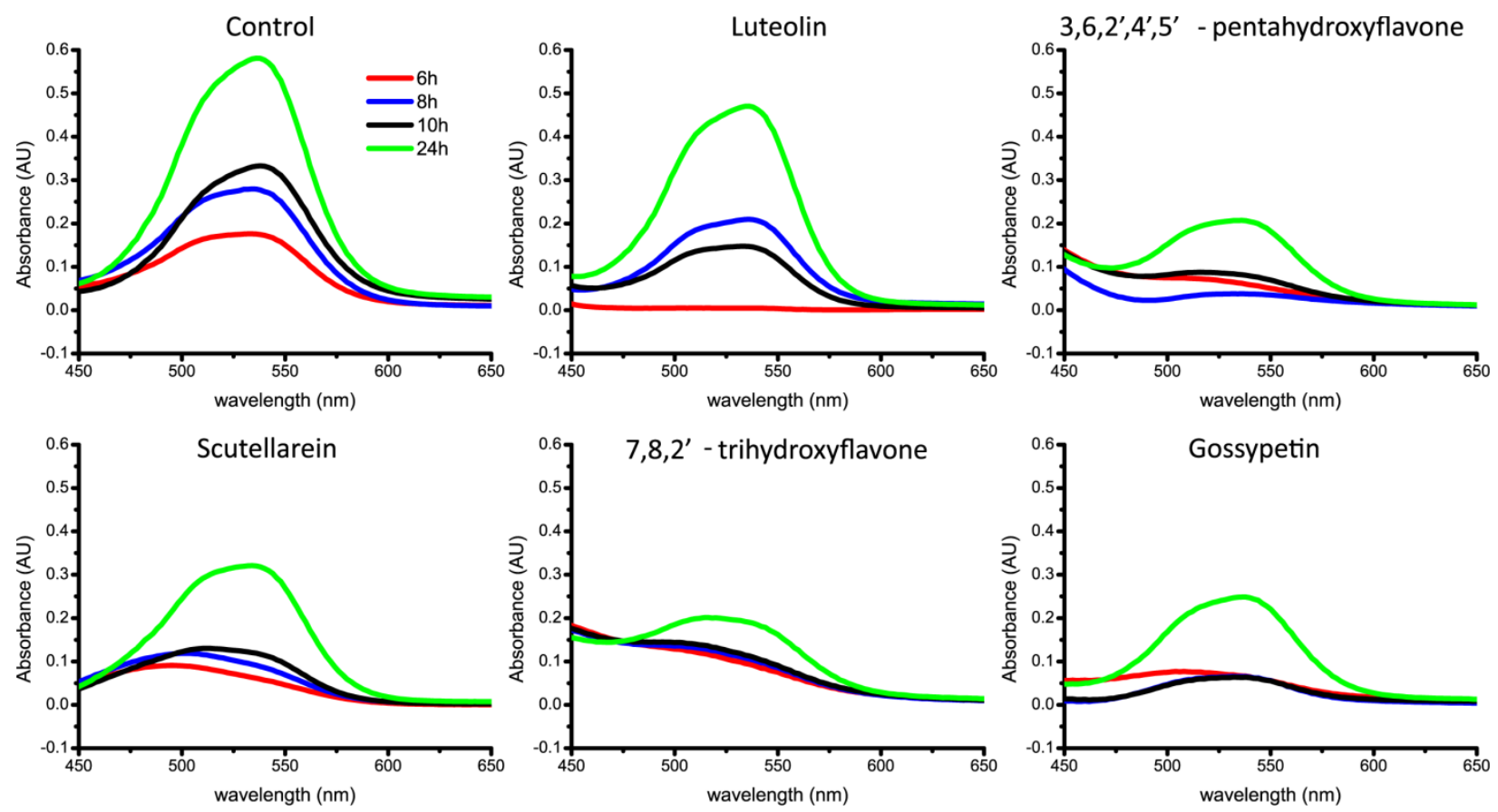

Figure 4. Aggregation of alpha-synuclein in the presence of flavones followed by Congo Red differential spectra. The ligand/protein ratio was $3: 2$.

Microscopy data revealed that amyloid-like fibrils still can be formed in the presence of inhibitors (Fig. 5); however some differences are worth mentionining. In the absence of flavones and in the presence of luteolin big fibril clumps can be found. In the presence of scutellarein and 7,8,2'-trihydroxyflavone, images contain mostly separate $4 \mathrm{~nm}$ diameter fibrils, while in the presence of 3,6,2',4',5'-pentahydroxyflavone and gossypetin some fibril clumps and a number of 2-4 $\mathrm{nm}$ oligomers can be found. It suggests that all tested flavones but luteolin change not only

247 time of aggregation but also the amount and the nature of final aggregates. 

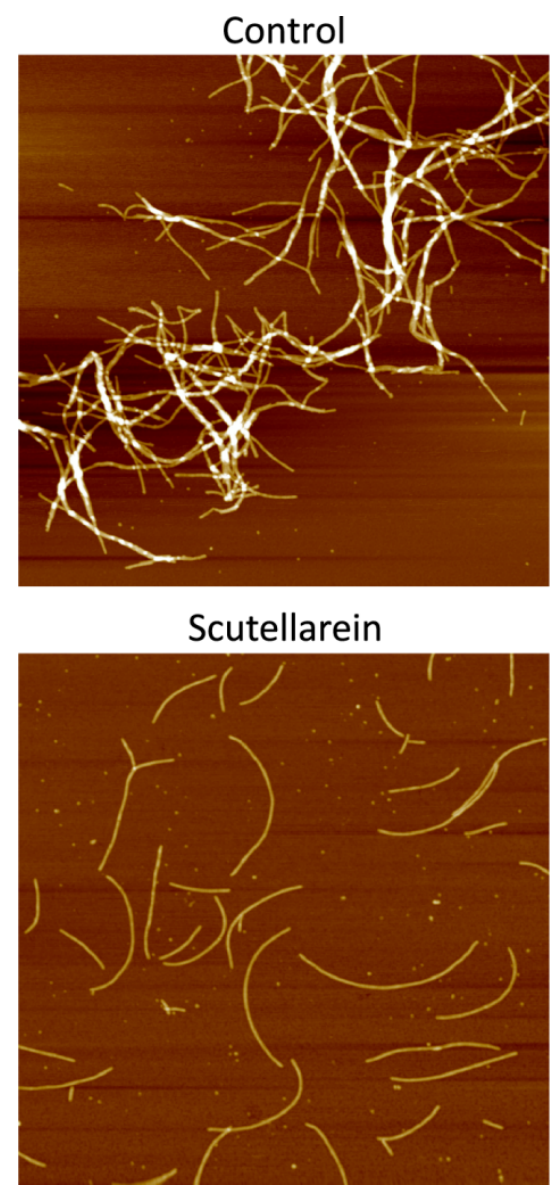

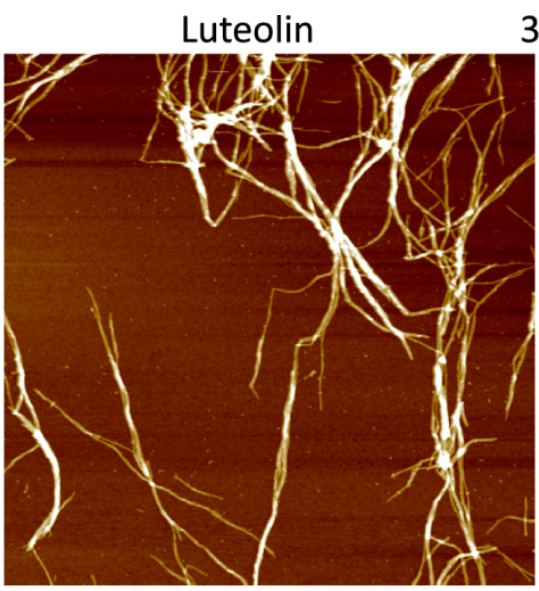

$7,8,2^{\prime}$ - trihydroxyflavone

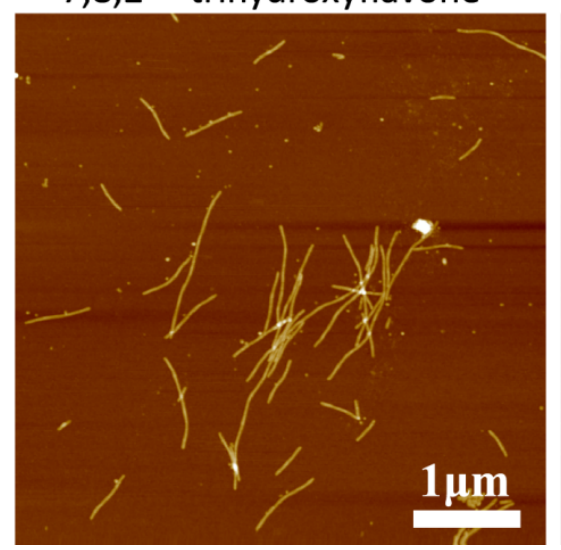

$3,6,2^{\prime}, 4^{\prime}, 5^{\prime}$ - pentahydroxyflavone
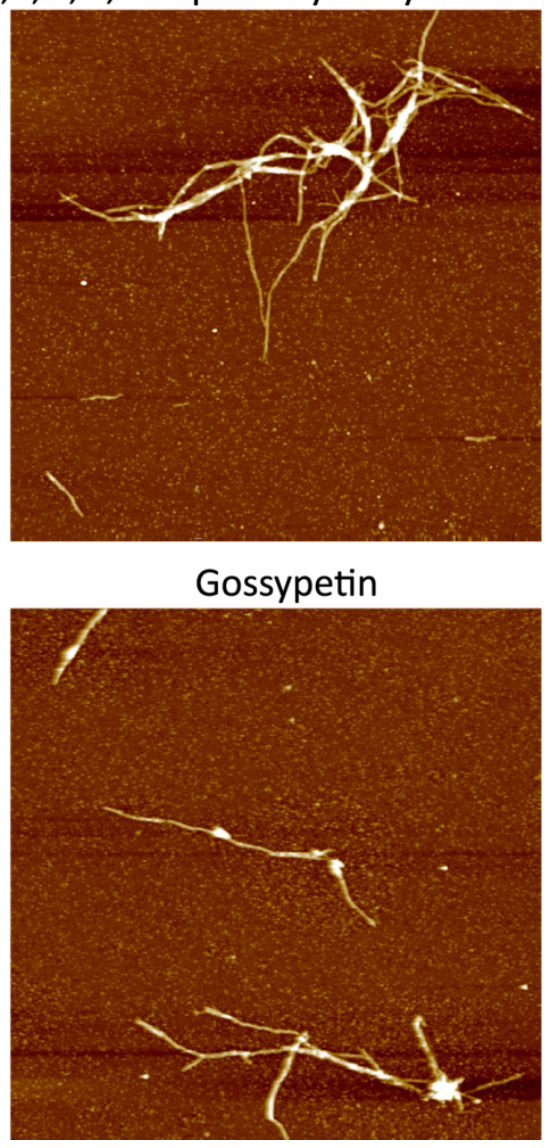

249 Figure 5. AFM images of alpha synuclein aggregates. The ligand/protein ratio was 3:2.

251 Equimolar amounts of flavones had almost no influence on both ThT fluorescence intensity and

$252 t_{50}$ values of Abeta aggregation. In the figure 6 we show the data, obtained using up to 36 times

253 higher concentrations of compounds. Both fluorescence intensity and $t_{50}$ values of the

254 aggregation in the presence of gossypetin show only minor decreases when compared to the

255 control. In the presence of the highest used concentrations of other flavones, fluorescence

256 intensity strongly decreases, but the time of aggregation is not increased. Moreover, the

257 aggregation looks a little faster. 

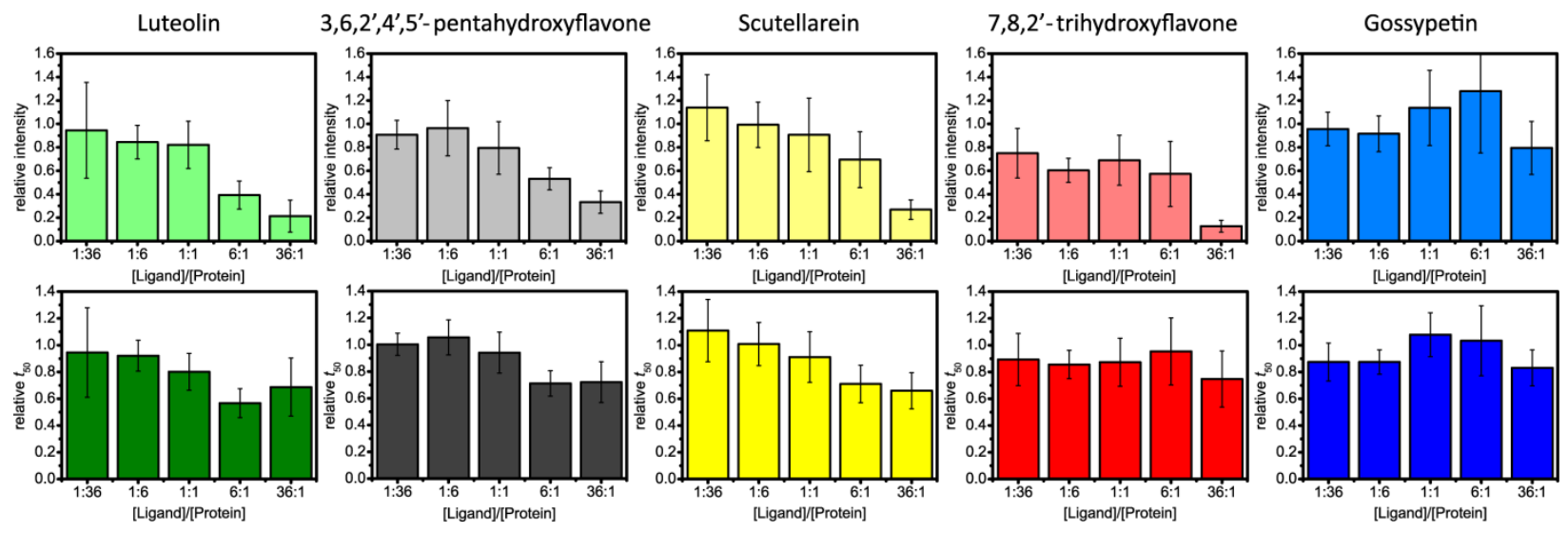

Figure 6. Effect of flavones on the aggregation of Abeta. Each flavone derivative is represented by different color. Relative ThT fluorescence intensities are shown in light colors (top row) and relative halftimes of aggregation in dark colors (bottom row).

Complementary analysis using Congo Red spectroscopic assay showed some differences (Fig.

7). The spectral maxima at $\sim 540 \mathrm{~nm}$ grow fast in the control sample and in the presence of luteolin, 3,6,2',4',5'-pentahydroxyflavone and gossypetin. In samples with scuttelarein and maxima as in the control sample within 3 hours. It can be interpreted as an inhibition of the initial steps of fibrillation; however the effect is not major. 

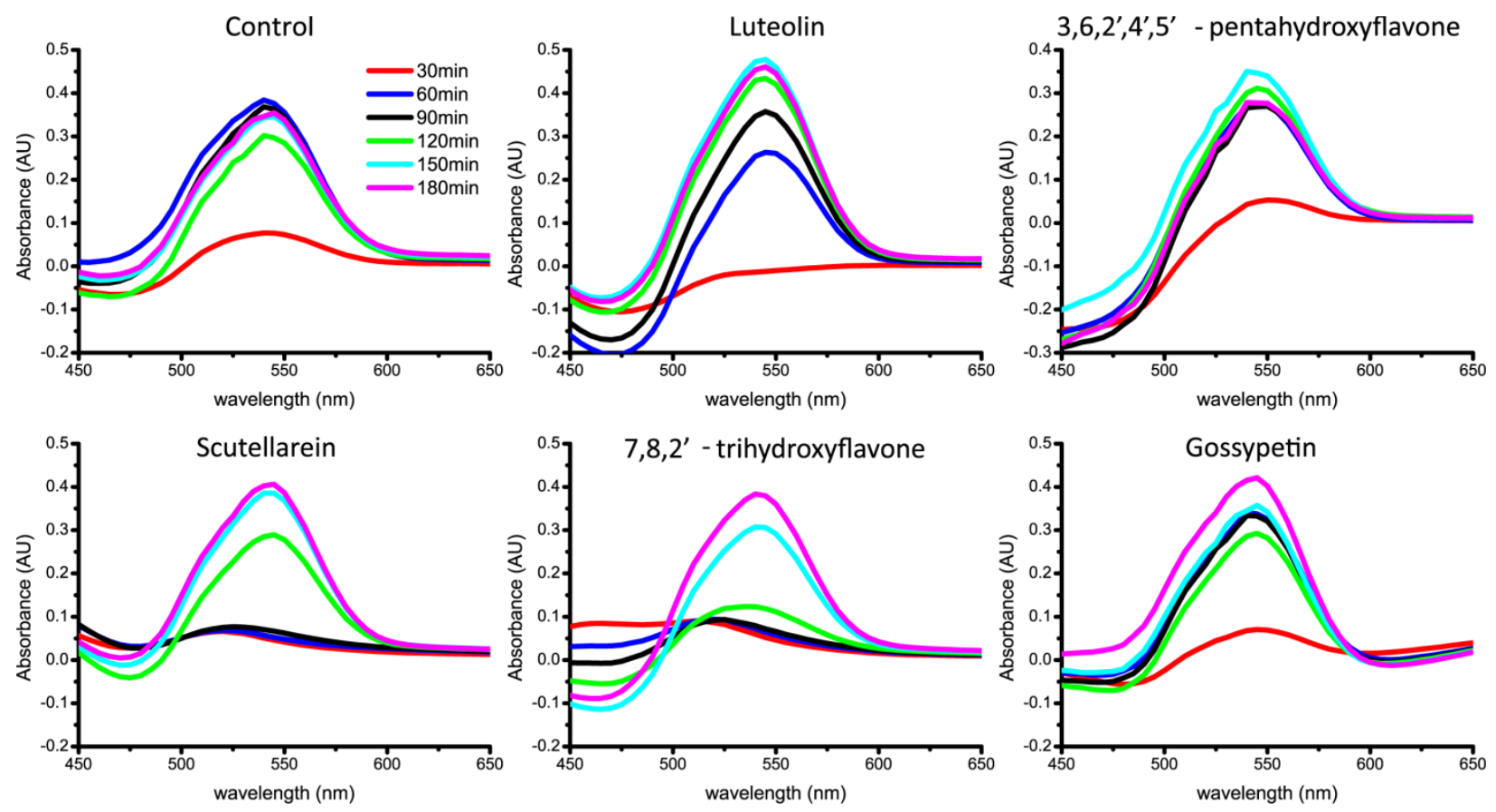

Figure 7. Aggregation of Abeta in the presence of flavones followed by Congo Red differential spectra. Abeta concentration was $15 \mu \mathrm{M}$. The ligand/protein ratio was 7:1.

No major differences were found in the AFM images of Abeta fibrils formed in the presence of different flavone derivatives (Fig. 8). The diameter of individual fibrils in all cases is in the range of $4-10 \mathrm{~nm}$ and the majority of fibrils are in larger clumps. 


\section{PeerJ Reviewing Manuscript}

Control

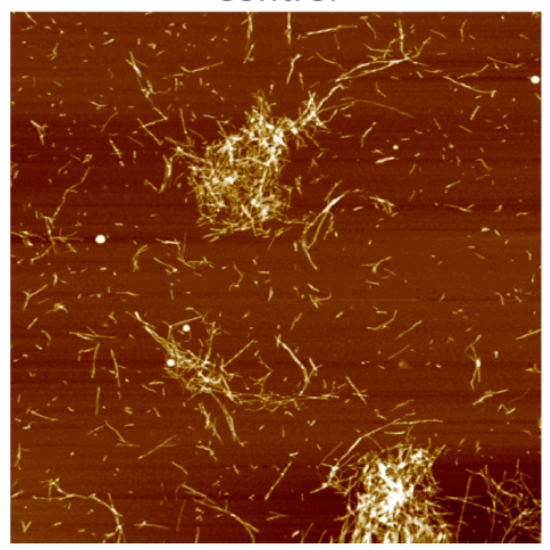

Scutellarein

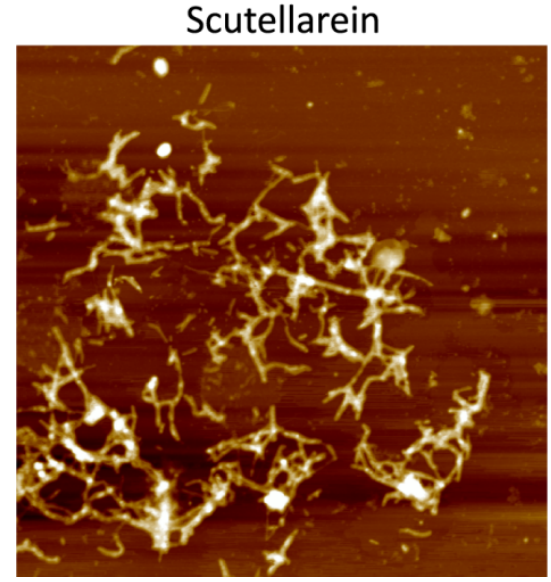

Luteolin

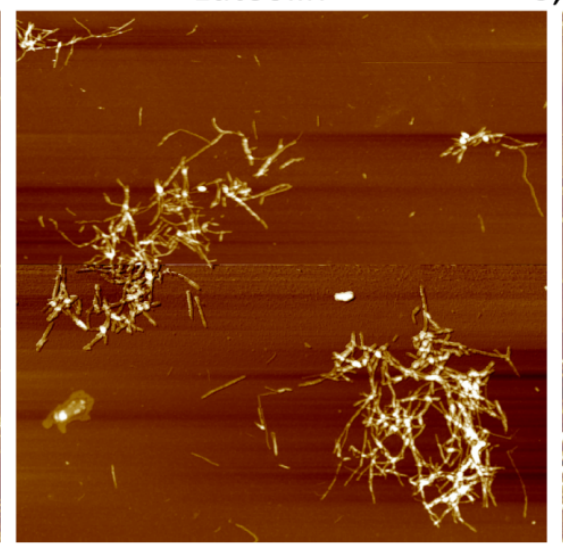

$7,8,2^{\prime}$ - trihydroxyflavone

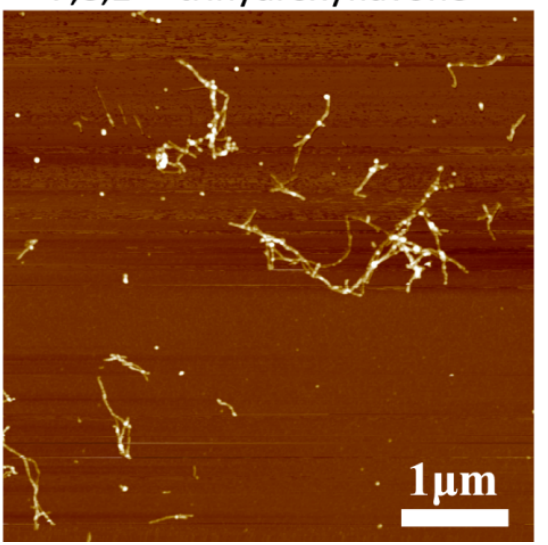

$3,6,2^{\prime}, 4^{\prime}, 5^{\prime}$ - pentahydroxyflavone

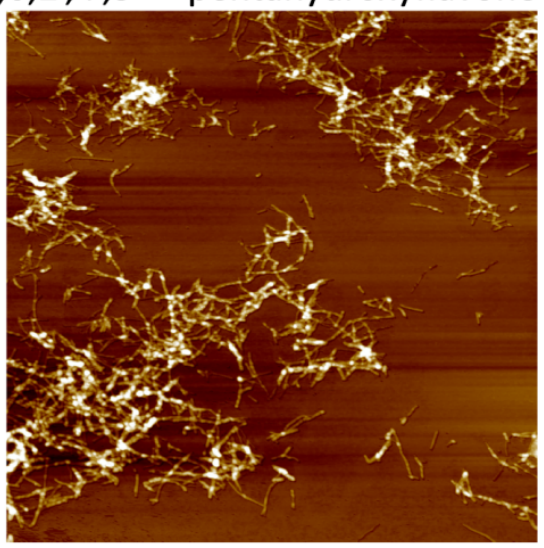

Gossypetin

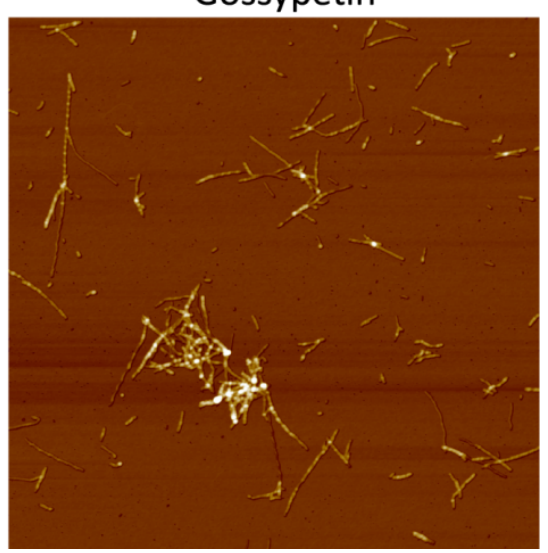

Figure 8. AFM images of Abeta aggregates. Abeta concentration was $15 \mu \mathrm{M}$. The ligand/protein ratio was 7:1.

As a positive control of inhibition we used EGCG (Fig. 9). In case of alpha-synuclein it works similar to most of the tested flavones. ThT fluorescence intensity is decreased and time of aggregation is increased with higher EGCG concentrations (Fig. 9A). Congo Red differential spectral maxima rise slowly and final absorbance values are low (Fig. 9B). Finally, a number of oligomers were detected together with the final fibrils (Fig. 9C). The only difference is higher

285 ThT fluorescence intensities at low EGCG concentrations. In the case of Abeta, ThT intensity

286 decrease and fluctuations of aggregation time are also comparable to the data seen in the 287 presence of flavones (Fig. 9D). The Congo Red spectral maximum starts to rise after 2 hours, 
288 similarly to the cases of scuttelarein and 7,8,2'-trihydroxyflavone (Fig. 9E). The diameter of 289 Abeta fibrils formed in the presence of EGCG is also similar to the control sample; however the 290 amount of fibrils found on the mica is lower.

A
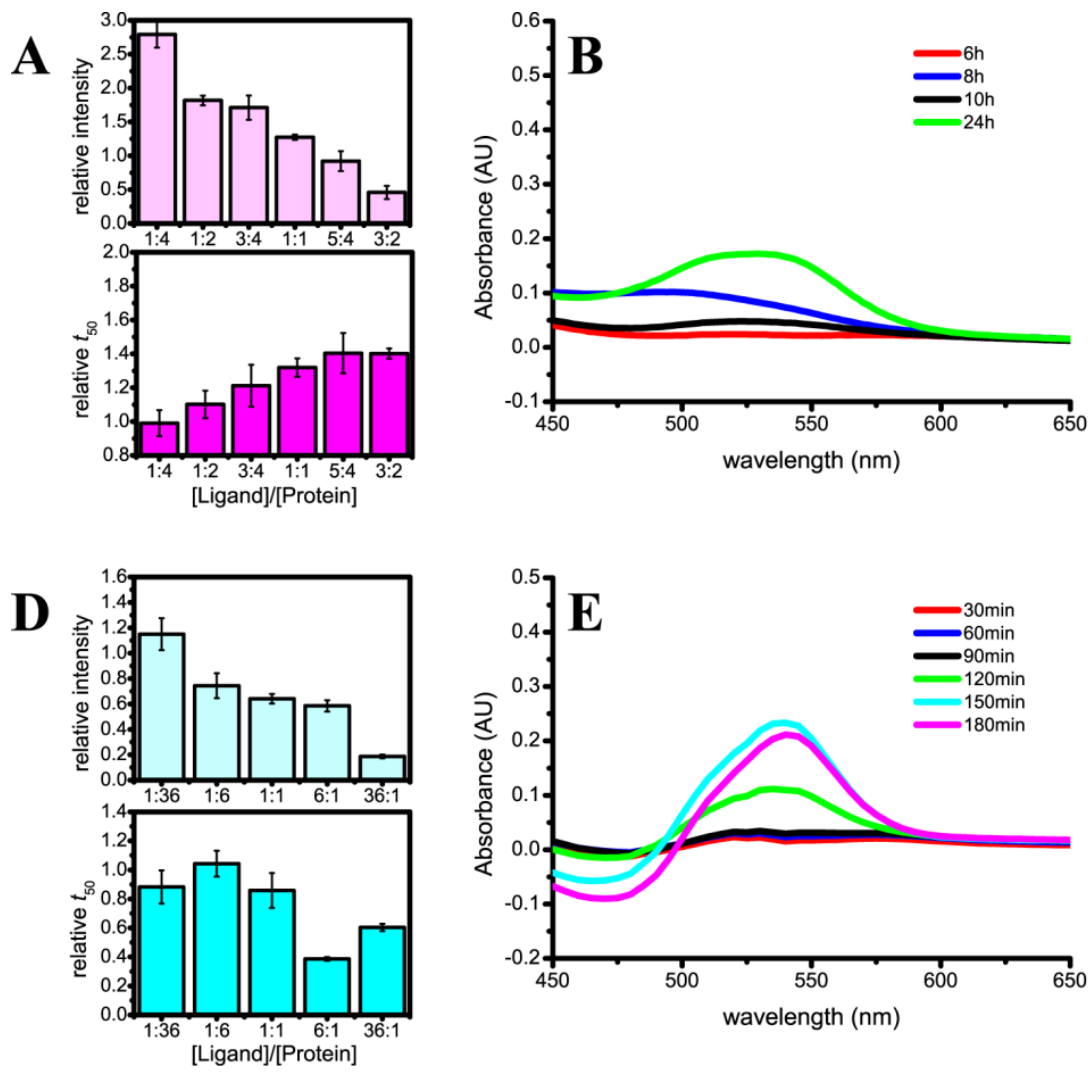
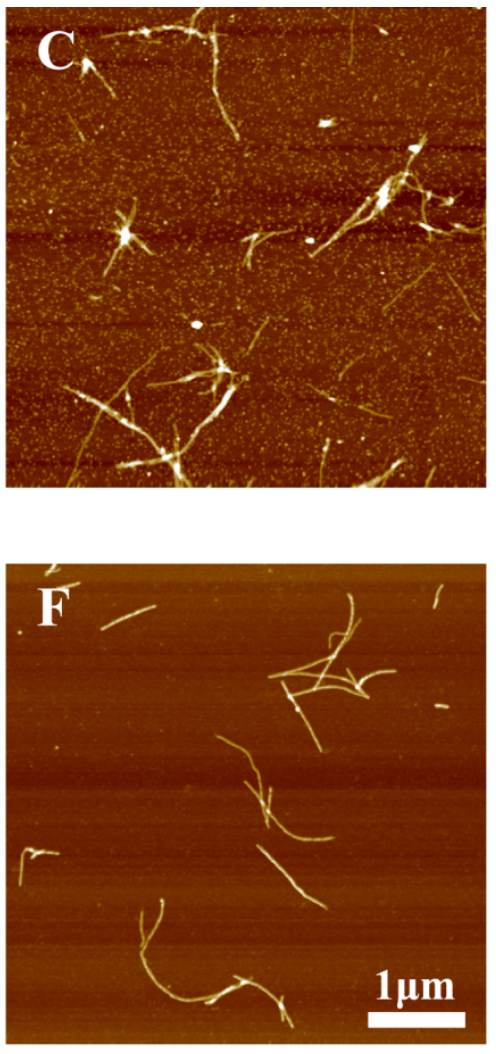

Figure 9. Aggregation of alpha-synuclein (A-C) and Abeta (D-F) in presence of EGCG, Illustrated by relative ThT intensity and $t_{50}$ (A and D), Congo Red differential spectra (B and E) and AFM images of final aggregates (C and F). Abeta concentration used for Congo Red and AFM studies was $15 \mu \mathrm{M}$. The EGCG/Abeta ratio was 7:1, and EGCG/alpha-synuclein ratio was 3:2. 
299 We began the current study with hopes of finding a useful, generic inhibitor of amyloid fibril

300 formation. With the variety of literature reporting flavones as effective inhibitors, we previously

301 carried out an extensive screening of 265 commercially available flavone derivatives. The study

302 revealed a method for eliminating large numbers of false positives for fibril inhibition while still

303 using a simple method - ThT fluorescence. By measuring the time for $50 \%$ of maximal fibril

304 growth rather than absolute ThT fluorescence, we identified only five flavones that appreciably

305 inhibited insulin fibril formation (Malisauskas et al., 2015). In extending the study to look at the

306 effects of these five flavones on Abeta and alpha-synuclein, we found moderate to no inhibition

307 of fibril formation for either of these proteins. If there is an effective, generic inhibitor of fibril

308 formation to be found among flavone derivatives, it is not among the 265 commercially available

309 compounds.

310 Surprisingly, an expected positive control (EGCG) worked similar to some flavones. Our results

311 show that EGCG does not inhibit Abeta fibrillation, leading to the conclusion that it is not the

312 universal inhibitor implied by the collection of previous reports. In fact, our ThT data on

313 aggregation of alpha-synuclein and Abeta in the presence of EGCG are comparable to the

314 previously published (Ehrnhoefer et al., 2008) and the main controversy comes from the

315 microscopy data. Ehrnhoefer et al found just oligomers and no fibrils in alpha-synuclein and

316 Abeta samples in the presence of EGCG (Ehrnhoefer et al., 2008); however we can see mostly

317 fibrils in Abeta samples (Fig. 9F) and fibrils together with oligomers in alpha-synuclein samples

318 (Fig. 9C). Having in mind low stability of EGCG at neutral pH (Zhu et al., 1997) and the fact

319 that EGCG effect on amyloid is dependent on auto-oxidation of EGCG (Palhano et al., 2013),

320 slightly different conditions for our experiments (compared to Ehrnhoefer et al) may be the 
321 reason of controversial data. If this is true, then even EGCG cannot be called universal inhibitor

322 of amyloid aggregation, as inhibition may be dependent on the environmental conditions.

323 Failure appears to be a common state of affairs when discussing drug development for 324 Alzheimer's disease (Becker, Greig \& Giacobini, 2008; Rosenblum, 2014; Schneider et al., 325 2014). While failures in clinical trials involve much greater complexity than the (relatively) 326 simple screening of small molecule amyloid inhibitors, many candidate molecules for drug trials 327 come from high-throughput screening, so the method of screening is directly responsible for the 328 selection of the right targets. As noted in the introduction and confirmed in our current study, 329 false positive results for amyloid inhibition can lead to extensive resources expended 330 characterizing the effects of molecules that will ultimately be of no benefit in treating disease.

331 Had we relied solely on maximum ThT fluorescence intensity to determine inhibition, four out of 332 the five flavones studied would be indicated as inhibitors of Abeta aggregation. In fact, luteolin 333 was already mentioned as an inhibitor previously (Akaishi et al., 2008). Of course, there is 334 always thorough testing between initial screenings of drug candidates and clinical trials, but our 335 simple expedient of measuring a kinetic feature of fibril aggregation has proven sufficient to 336 eliminate many false positives with Abeta and alpha-synuclein fibrillation, in addition to our 337 previous observations for insulin fibrillation.

338 Measuring the time to half maximal ThT fluorescence has proved so effective in the case of 265

339 flavones that we reduced a large false positive rate for inhibition to the point where we can 340 demonstrate that there is no universal amyloid inhibitor among these candidate compounds. The 341 more labor intensive, additional studies of measuring Congo Red absorbance spectra and AFM 342 added some interesting information, but did not improve on our ability to quickly reduce a large 343 set of candidate inhibitors to a small set of more promising candidates. However, care is clearly 
344 required before drawing sweeping conclusions from these simple results as illustrated by the

345 discrepancies between our observations and those published previously regarding EGCG as an

346 inhibitor of Abeta and alpha-synuclein fibrillation (Ehrnhoefer et al., 2008; Bieschke et al.,

347 2010). These controversial data emphasize the ambiguity of methods applied for the detection of

348 anti-amyloid compounds and suggests that differences in enviromental conditions must be

349 carefully examined in seeking a full understanding of inhibitor effects.

350

351

352

353

354

355

356

357

\section{Acknowlegments}

The expression plasmid (pRK 172) harbouring gene for human alpha-synuclein was kindly provided by Dr. L.A. Morozova-Roche and Dr. M. Malisauskas. The expression plasmid with Abeta42 gene was kindly provided by Dr. C. Cullin. The authors thank Dr. M. Jankunec for the help with AFM.

\section{References}

Akaishi T, Morimoto T, Shibao M, Watanabe S, Sakai-Kato K, Utsunomiya-Tate N, Abe K. 2008. Structural requirements for the flavonoid fisetin in inhibiting fibril formation of amyloid beta protein. Neuroscience Letters 444:280-285.

Becker RE, Greig NH, Giacobini E. 2008. Why do so many drugs for Alzheimer's disease fail in development? Time for new methods and new practices? Journal of Alzheimer's disease : JAD 15:303-325.

Bieschke J, Russ J, Friedrich RP, Ehrnhoefer DE, Wobst H, Neugebauer K, Wanker EE. 2010. EGCG remodels mature alpha-synuclein and amyloid-beta fibrils and reduces cellular toxicity. Proceedings of the National Academy of Sciences of the United States of America 107:7710-7715.

Bieschke J. 2013. Natural Compounds May Open New Routes to Treatment of Amyloid Diseases. Neurotherapeutics 10:429-439. 
Buell AK, Galvagnion C, Gaspar R, Sparr E, Vendruscolo M, Knowles TPJ, Linse S, Dobson CM. 2014. Solution conditions determine the relative importance of nucleation and growth processes in $\alpha$-synuclein aggregation. Proceedings of the National Academy of Sciences of the United States of America 111:7671-7676.

Chandrashekaran IR, Adda CG, MacRaild C a., Anders RF, Norton RS. 2010. Inhibition by flavonoids of amyloid-like fibril formation by plasmodium falciparum merozoite surface protein 2. Biochemistry 49:5899-5908.

Chandrashekaran IR, Adda CG, MacRaild C a., Anders RF, Norton RS. 2011. EGCG disaggregates amyloid-like fibrils formed by Plasmodium falciparum merozoite surface protein 2. Archives of Biochemistry and Biophysics 513:153-157.

Chiti F, Dobson CM. 2006. Protein misfolding, functional amyloid, and human disease. Annual review of biochemistry 75:333-366.

Doig AJ, Derreumaux P. 2015. Inhibition of protein aggregation and amyloid formation by small molecules. Current opinion in structural biology 30:50-6.

Ehrnhoefer DE, Duennwald M, Markovic P, Wacker JL, Engemann S, Roark M, Legleiter J, Marsh JL, Thompson LM, Lindquist S, Muchowski PJ, Wanker EE. 2006. Green tea (-)epigallocatechin-gallate modulates early events in huntingtin misfolding and reduces toxicity in Huntington's disease models. Human Molecular Genetics 15:2743-2751.

Ehrnhoefer DE, Bieschke J, Boeddrich A, Herbst M, Masino L, Lurz R, Engemann S, Pastore A, Wanker EE. 2008. EGCG redirects amyloidogenic polypeptides into unstructured, offpathway oligomers. Nature structural \& molecular biology 15:558-566.

Feng Y, Wang XP, Yang SG, Wang YJ, Zhang X, Du XT, Sun XX, Zhao M, Huang L, Liu RT. 2009. Resveratrol inhibits beta-amyloid oligomeric cytotoxicity but does not prevent oligomer formation. NeuroToxicology 30:986-995.

Ferreira N, Cardoso I, Domingues MR, Vitorino R, Bastos M, Bai G, Saraiva MJ, Almeida MR. 2009. Binding of epigallocatechin-3-gallate to transthyretin modulates its amyloidogenicity. FEBS Letters 583:3569-3576.

Ferreira N, Saraiva MJ, Almeida MR. 2011. Natural polyphenols inhibit different steps of the process of transthyretin (TTR) amyloid fibril formation. FEBS Letters 585:2424-2430.

Foderà V, Groenning M, Vetri V, Librizzi F, Spagnolo S, Cornett C, Olsen L, Van De Weert M, Leone M. 2008. Thioflavin T hydroxylation at basic $\mathrm{pH}$ and its effect on amyloid fibril detection. Journal of Physical Chemistry B 112:15174-15181. 
401

402

403

404

405

406

407

408

409

410

411

412

413

414

415

416

417

418

419

420

421

422

423

424

425

426

427

428

429

430

431

432

Ghosh S, Pandey NK, Dasgupta S. 2013. (-)-Epicatechin gallate prevents alkali-salt mediated fibrillogenesis of hen egg white lysozyme. International Journal of Biological Macromolecules 54:90-98.

Gopalswamy M, Kumar A, Adler J, Baumann M, Henze M, Kumar ST, Fändrich M, Scheidt H a., Huster D, Balbach J. 2015. Structural characterization of amyloid fibrils from the human parathyroid hormone. Biochimica et Biophysica Acta (BBA) - Proteins and Proteomics 1854:249-257.

Hellstrand E, Boland B, Walsh DM, Linse S. 2010. Amyloid beta-protein aggregation produces highly reproducible kinetic data and occurs by a two-phase process. ACS Chemical Neuroscience 1:13-18.

Herva ME, Zibaee S, Fraser G, Barker R a., Goedert M, Spillantini MG. 2014. Anti-amyloid Compounds Inhibit alpha-Synuclein Aggregation Induced by Protein Misfolding Cyclic Amplification (PMCA). Journal of Biological Chemistry 289:11897-11905.

Hudson S a., Ecroyd H, Dehle FC, Musgrave IF, Carver J a. 2009a. (-)-Epigallocatechin-3Gallate (EGCG) Maintains $\kappa$-Casein in Its Pre-Fibrillar State without Redirecting Its Aggregation Pathway. Journal of Molecular Biology 392:689-700.

Hudson S a., Ecroyd H, Kee TW, Carver J a. 2009b. The thioflavin T fluorescence assay for amyloid fibril detection can be biased by the presence of exogenous compounds. FEBS Journal 276:5960-5972.

Ladiwala AR a, Lin JC, Bale SS, Marcelino-Cruz AM, Bhattacharya M, Dordick JS, Tessier PM. 2010. Resveratrol selectively remodels soluble oligomers and fibrils of amyloid Abeta into off-pathway conformers. Journal of Biological Chemistry 285:24228-24237.

Malisauskas R, Botyriute A, Cannon JG, Smirnovas V. 2015. Flavone Derivatives as Inhibitors of Insulin Amyloid-Like Fibril Formation. Plos One 10:e121231.

Mangialasche F, Solomon A, Winblad B, Mecocci P, Kivipelto M. 2010. Alzheimer's disease: clinical trials and drug development. The Lancet Neurology 9:702-716.

Meng F, Abedini A, Plesner A, Verchere CB, Raleigh DP. 2010. The Flavanol (-)epigallocatechin 3-gallate inhibits amyloid formation by islet amyloid polypeptide, disaggregates amyloid fibrils, and protects cultured cells against IAPP-induced toxicity. Biochemistry 49:8127-8133.

Mishra R, Sellin D, Radovan D, Gohlke A, Winter R. 2009. Inhibiting islet amyloid polypeptide fibril formation by the red wine compound resveratrol. ChemBioChem 10:445-449. 
Nelson R, Eisenberg D. 2006. Structural Models of Amyloid-Like Fibrils. Advances in Protein Chemistry 73:235-282.

Nilsson MR. 2004. Techniques to study amyloid fibril formation in vitro. Methods 34:151-160.

Noor H, Cao P, Raleigh DP. 2012. Morin hydrate inhibits amyloid formation by islet amyloid polypeptide and disaggregates amyloid fibers. Protein Science 21:373-382.

Noormägi A, Primar K, Tõugu V, Palumaa P. 2012. Interference of low-molecular substances with the thioflavin-T fluorescence assay of amyloid fibrils. Journal of Peptide Science 18:59-64.

Ono K, Yoshiike Y, Takashima A, Hasegawa K, Naiki H, Yamada M. 2003. Potent antiamyloidogenic and fibril-destabilizing effects of polyphenols in vitro: Implications for the prevention and therapeutics of Alzheimer's disease. Journal of Neurochemistry 87:172181.

Palhano FL, Lee J, Grimster NP, Kelly JW. 2013. Toward the molecular mechanism(s) by which EGCG treatment remodels mature amyloid fibrils. Journal of the American Chemical Society 135:7503-7510.

Rambold AS, Miesbauer M, Olschewski D, Seidel R, Riemer C, Smale L, Brumm L, Levy M, Gazit E, Oesterhelt D, Baier M, Becker CFW, Engelhard M, Winklhofer KF, Tatzelt J. 2008. Green tea extracts interfere with the stress-protective activity of PrPC and the formation of PrPSc. Journal of Neurochemistry 107:218-229.

Roberts BE, Duennwald ML, Wang H, Chung C, Lopreiato NP, Sweeny E a, Knight MN, Shorter J. 2009. A synergistic small-molecule combination directly eradicates diverse prion strain structures. Nature chemical biology 5:936-946.

Roberts BE, Shorter J. 2008. Escaping amyloid fate. Nature structural \& molecular biology 15:544-546.

Rosenblum WI. 2014. Why Alzheimer trials fail: Removing soluble oligomeric beta amyloid is essential, inconsistent, and difficult. Neurobiology of Aging 35:969-974.

Schägger H. 2006. Tricine-SDS-PAGE. Nature protocols 1:16-22.

Schneider LS, Mangialasche F, Andreasen N, Feldman H, Giacobini E, Jones R, Mantua V, Mecocci P, Pani L, Winblad B, Kivipelto M. 2014. Clinical trials and late-stage drug development for Alzheimer's disease: An appraisal from 1984 to 2014. Journal of Internal Medicine 275:251-283. 
Seneci P. 2015. Chemical Modulators of Protein Misfolding and Neurodegenerative Disease. Elsevier.

Studier FW. 2005. Protein production by auto-induction in high density shaking cultures. Protein expression and purification 41:207-234.

Trivella DBB, dos Reis C V., Lima LMTR, Foguel D, Polikarpov I. 2012. Flavonoid interactions with human transthyretin: Combined structural and thermodynamic analysis. Journal of Structural Biology 180:143-153.

Ushikubo H, Watanabe S, Tanimoto Y, Abe K, Hiza A, Ogawa T, Asakawa T, Kan T, Akaishi T. 2012. 3,3',4',5,5'-Pentahydroxyflavone is a potent inhibitor of amyloid $\beta$ fibril formation. Neuroscience Letters 513:51-56.

Vignaud H, Bobo C, Lascu I, Sörgjerd KM, Zako T, Maeda M, Salin B, Lecomte S, Cullin C. 2013. A structure-toxicity study of $A ß 42$ reveals a new anti-parallel aggregation pathway. PLOS ONE 8:1-13.

Walsh DM, Thulin E, Minogue AM, Gustavsson N, Pang E, Teplow DB, Linse S. 2009. A facile method for expression and purification of the Alzheimer's disease-associated amyloid $\beta$ peptide. FEBS Journal 276:1266-1281.

Wang SH, Dong XY, Sun Y. 2012. Effect of (-)-epigallocatechin-3-gallate on human insulin fibrillation/aggregation kinetics. Biochemical Engineering Journal 63:38-49.

Wobst HJ, Sharma A, Diamond MI, Wanker EE, Bieschke J. 2015. The green tea polyphenol $(-)$-epigallocatechin gallate prevents the aggregation of tau protein into toxic oligomers at substoichiometric ratios. FEBS Letters 589:77-83.

Zhu QY, Zhang A, Tsang D, Huang Y, Chen Z-Y. 1997. Stability of green tea catechins. J. Agric. Food Chem. 45:4624-4628. 